\title{
Assessment of 4-(Dimethylamino)pyridine as a Capping Agent for Gold
}

Nanoparticles

\section{Valérie J. Gandubert and R. Bruce Lennox}

Department of Chemistry, McGill University, 801 Sherbrooke Street West, Montréal, Québec H3A 2K6, Canada

\section{Supporting Information}
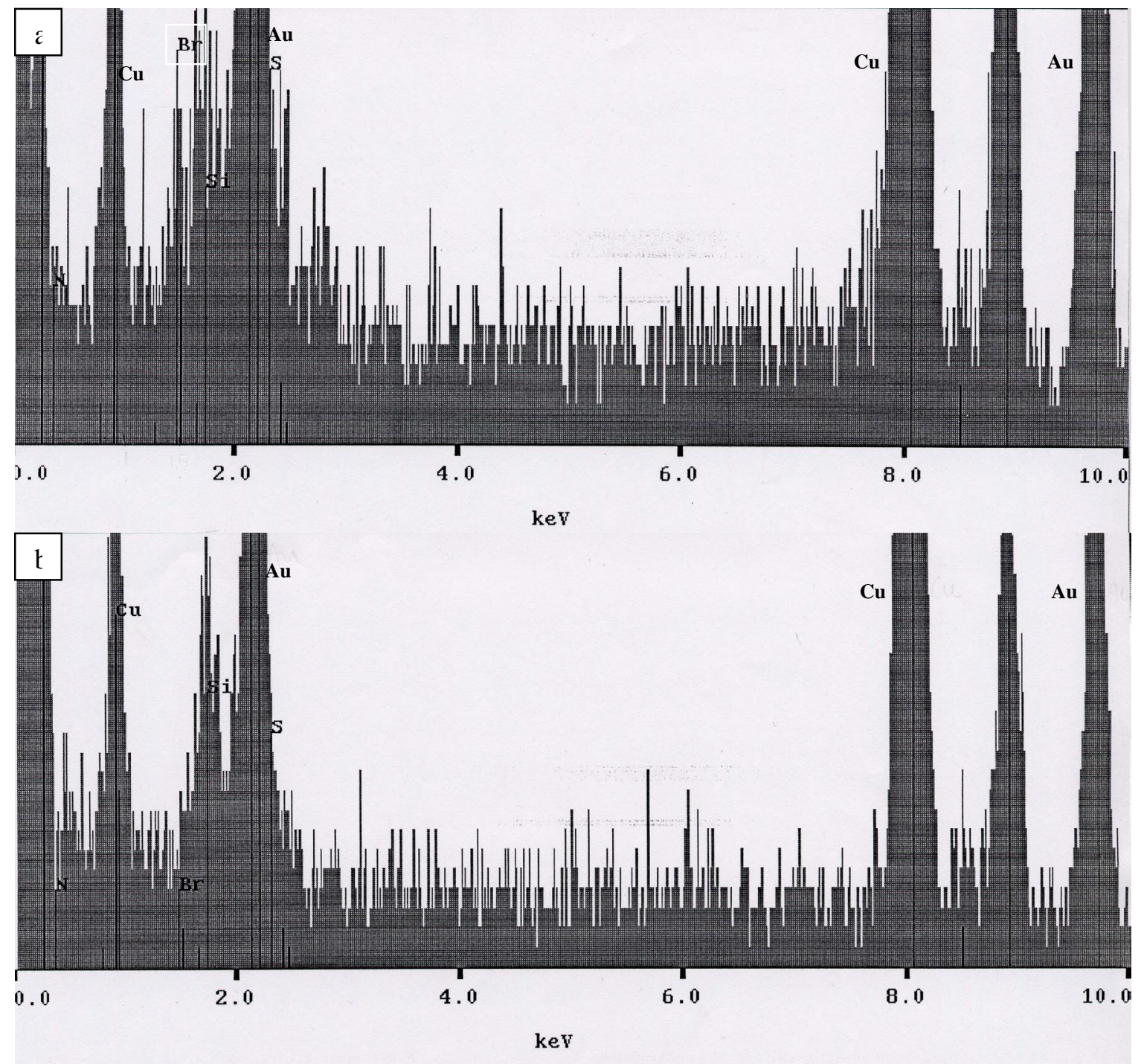

Figure S1. EDX spectra of (a) TOAB-Au nanoparticles, (b) DMAP-Au nanoparticles. 


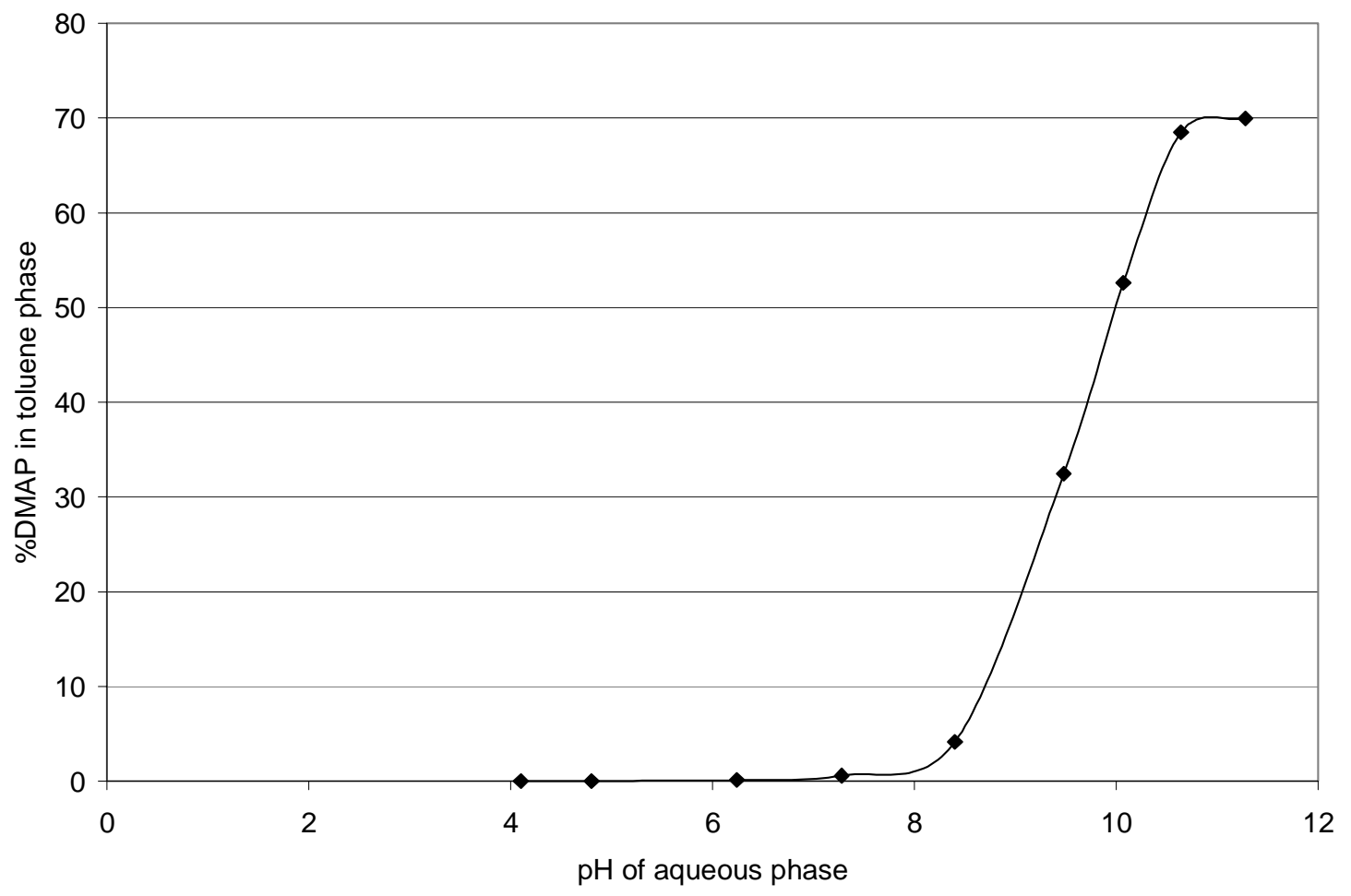

Figure S2. Percentage of DMAP in the toluene phase as a function of the $\mathrm{pH}$ of the DMAP aqueous phase. 


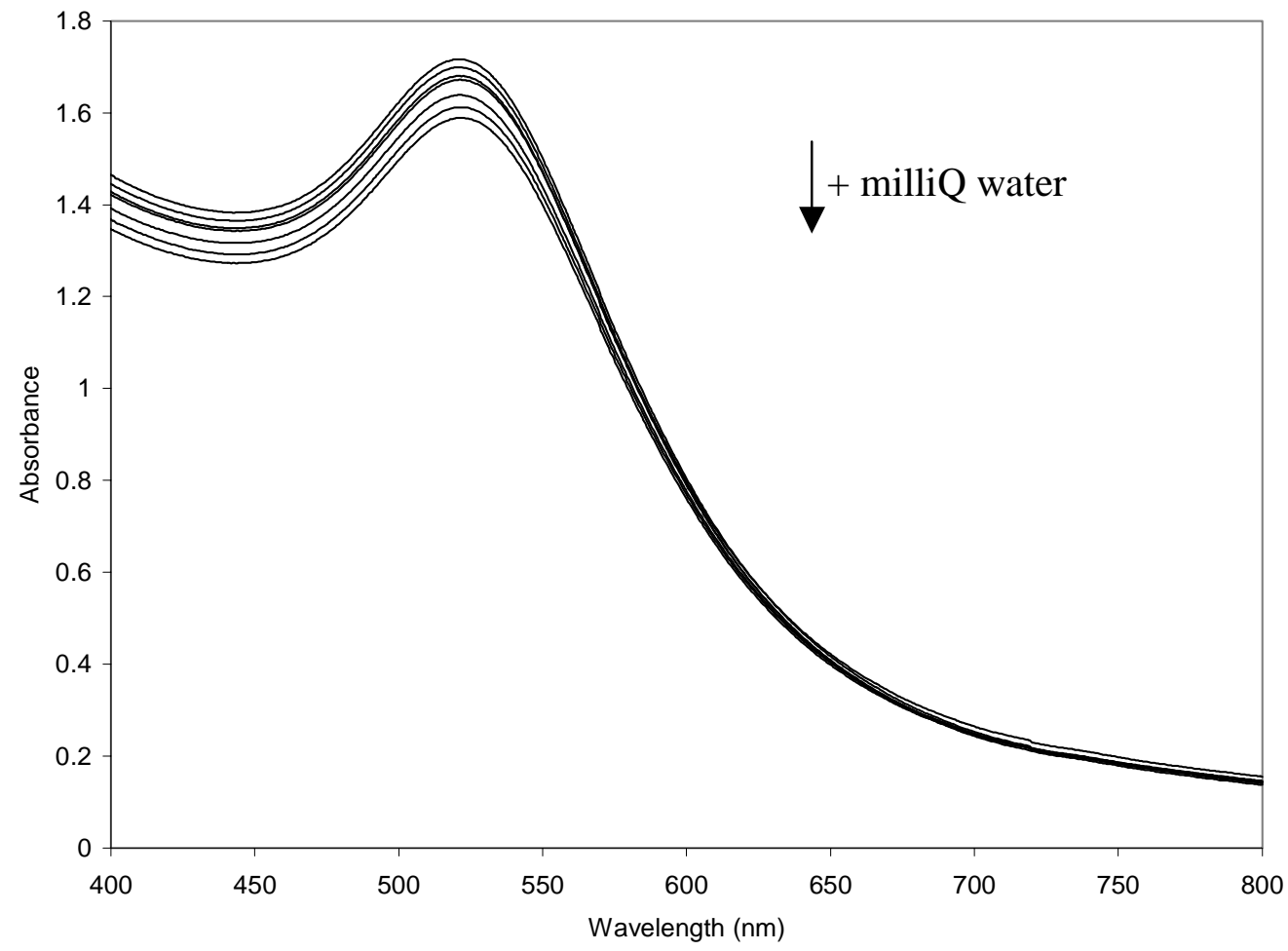

Figure S3. UV-Vis absorption spectra of aqueous dispersion of DMAP-Au nanoparticles before (top curve) and after successive additions of $100 \mu \mathrm{L}$ of milliQ water. 


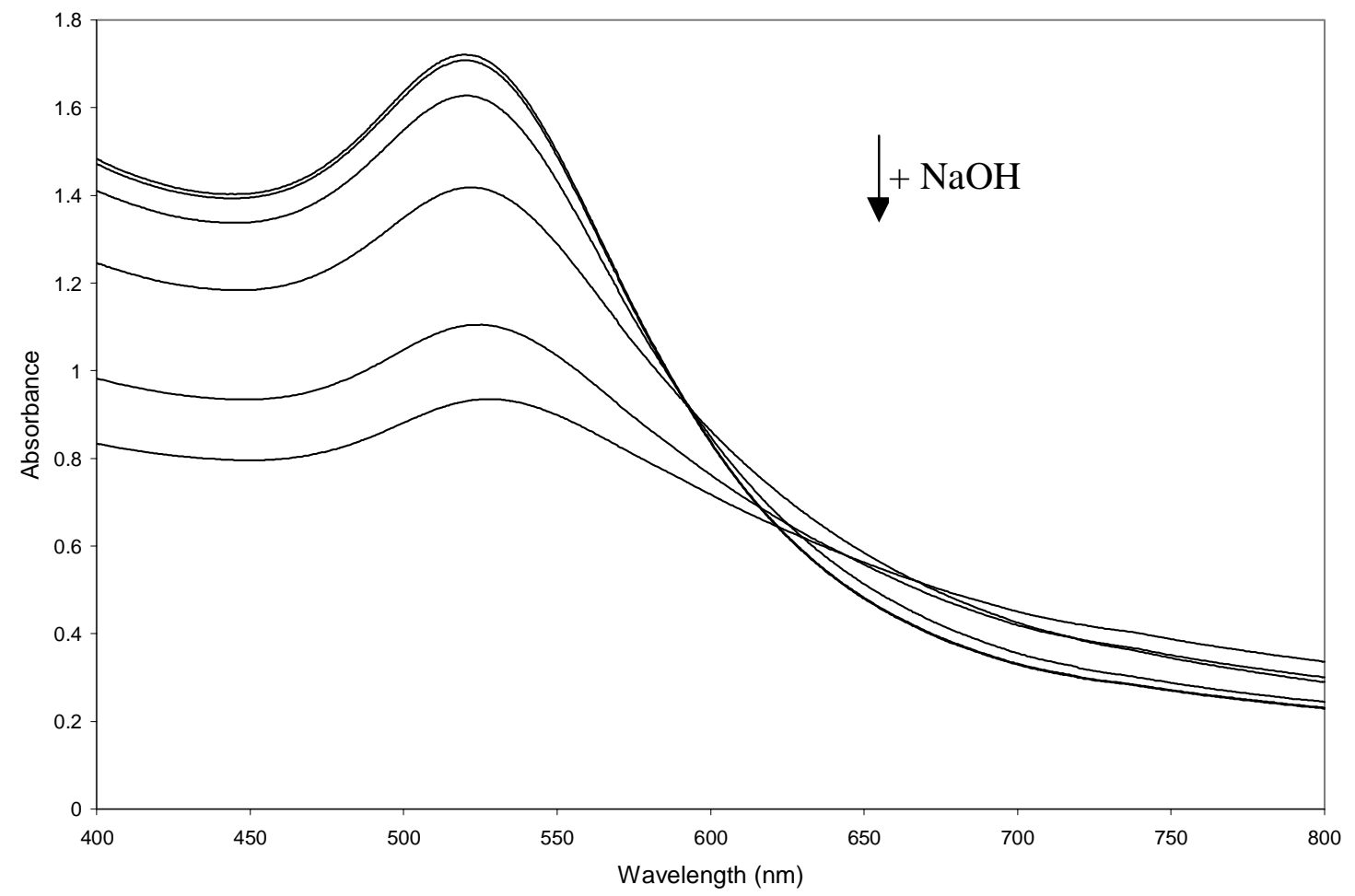

Figure S4. UV-Vis absorption spectra of aqueous dispersion of DMAP-Au nanoparticles brought to various pH's: 10.6 (initial $\mathrm{pH}$ ), 12.8, 13.0, 13.3, 13.7, and 13.8 (from top to bottom). The sodium hydroxide concentration in the sample is respectively $0 \mathrm{mM}, 98 \mathrm{mM}$, $180 \mathrm{mM}, 375 \mathrm{mM}, 1.26 \mathrm{M}, 1.80 \mathrm{M}$. 


\section{Electrochemical Measurements}

Solutions: All solutions were prepared from Milli-Q water in acid-washed glassware. The supporting electrolyte was $40 \mathrm{mM} \mathrm{KClO}_{4}$, which was chosen because perchlorate ions show no specific adsorption on gold. A $6 \mathrm{mM}$ DMAP and $0.85 \mathrm{M} \mathrm{HClO}_{4}$ stock solutions were prepared. All the solutions were degassed with argon for at least 1 hour before each experiment. During the experiment, argon was passed over the top of the solution. The experiments were carried out at $25^{\circ} \mathrm{C}$.

Electrodes: The working electrode was a polycrystalline gold bead which was formed by melting a gold wire. The area of the electrode was estimated by measuring the capacity of the electrode in $40 \mathrm{mM} \mathrm{KClO}$ and scaled to the known capacitance of polycrystalline gold at negative potentials. The counter electrode consisted of a gold coil of wire. An external $\mathrm{Ag} \mid \mathrm{AgCl}$ electrode was used as the reference electrode. All potentials reported are relative to $\mathrm{Ag} \mid \mathrm{AgCl}$. Before each experiment the gold working electrode was flame annealed and quenched with Milli-Q water.

Impedance measurements were performed using a Solartron SI 1287 potentiostat and a 1255B Frequency Response Analyzer (FRA). Frequency dependence measurements were made for a series of applied DC potentials with a range of frequencies between 5000 and $0.5 \mathrm{~Hz}$. These curves fit to a simple circuit of a resistor, to describe the electrolyte resistance, in series with a constant phase element (CPE) to describe the interfacial capacitance. A CPE was necessary as the frequency dispersion of a solid electrode causes deviation from an ideal capacitor [MacDonald, J.R., Impedance Spectroscopy, Wiley : New York, 1987]. In all cases the roughness parameter $(\alpha)$ for the CPE was $0.90<\alpha<$ 0.99 with a value of unity indicating a perfect capacitor. As the simple R-CPE circuit described the frequency dependence over a the range of applied DC potentials studied, single frequency capacity measurements could be made at $25 \mathrm{~Hz}$ with a DC potential sweep at $5 \mathrm{mV} / \mathrm{s}$. The amplitude of the ac perturbation was $5 \mathrm{mV} \mathrm{rms}$. From the FRA both the in-phase $\left(\mathrm{I}_{\mathrm{R}}\right)$ and out-of-phase $\left(\mathrm{I}_{\mathrm{C}}\right)$ currents were used to calculate the capacitance as a function of the $\mathrm{DC}$ potential $\mathrm{C}\left(E_{\mathrm{DC}}\right)$.

$C\left(E_{D C}\right)=\frac{I_{C}}{V_{a c} \omega}\left[1+\frac{I_{R}}{I_{C}}\right]^{2}$

where $V_{\mathrm{ac}}$ is the ac amplitude and $\omega$ is the angular frequency $(50 \pi)$. The $\mathrm{C}\left(E_{\mathrm{DC}}\right)$ plots are shown in Figure .

Capacity measurements provide information pertaining to the presence of adsorbing organic molecules on the metal electrode surfaces. The inner layer capacity if the interface can be described as a Helmholtz capacitor

$C=\frac{\varepsilon \varepsilon_{o}}{d}$

where $\varepsilon$ is the relative permittivity of the dielectric layer $\left(\varepsilon_{0}\right.$ is the permittivity of vacuum $\left.8.85 \times 10^{-12} \mathrm{C} \mathrm{V}^{-1} \mathrm{~m}^{-1}\right)$ that separates the metal from the diffuse part of the electrical double layer by a distance $d$. In the absence of an adsorbed organic layer, there is only a thin film of water having a high relative permittivity $(\varepsilon \sim 80)$. Organic films are 
characterized by roughly a factor of 10 lower permittivities and, as the adsorbing molecule is larger than water, a larger value of $d$. Consequently, an electrode modified by an organic film should display a lower capacity compared to the bare electrode interface.

The capacity was measured for the $40 \mathrm{mM} \mathrm{KClO} 4$ supporting electrolyte alone (grey line) and after addition of $0.1 \mathrm{mM}$ DMAP (black line). The $\mathrm{pH}$ of the $0.1 \mathrm{mM}$ DMAP +40 $\mathrm{mM} \mathrm{KClO} 4$ solution was independently determined to be 9.4 .

The grey line in Figure 3 is in excellent agreement with differential capacity curves of polycrystalline gold previously reported in the literature [Ianelli, A, Richer, J., Lipkowski, J, Langmuir, 1989, 466-473.]. The capacitive pit at $\sim 0 \mathrm{~V}$ is due to the diffuse layer minimum [Clavilier, J. J. Electroanal. Chem., 1977, 80, 101]. Comparison of the grey and black curves clearly indicates that the addition of DMAP to the $\mathrm{KClO}_{4}$ electrolyte results in a significant lowering of the capacity. At very negative potentials, the two curves nearly merge, which indicates that DMAP can be desorbed from the electrode if a sufficiently negative potential is applied to the electrode. As the potential is scanned in the positive direction there is a large pseudo capacitive peak which is attributable to the kinetics of potential induced DMAP adsorption. The region of potentials between $-0.4 \mathrm{~V}$ and $0.4 \mathrm{~V}$ are characterized by a quasi plateau in the capacity with a value of $9 \mu \mathrm{F} \mathrm{cm}^{-2}<C<12 \mu \mathrm{F} \mathrm{cm} \mathrm{cm}^{-2}$. For completeness we note the small capacitive peak at ca. $0.05 \mathrm{~V}$ which may represent a phase transition in the adsorbed layer but a more thorough investigation is beyond the scope of this paper. Returning the potential sweep in the negative direction reveals a qualitatively reversible process, although the hysterisis in the positive-going and negative-going sweeps indicates a kinetic influence. 


\section{Surface Plasmon Resonance Experiments}

Principle: SPR measures the intensity of reflection of an incident light on the backside of a gold-coated glass slide. SPR curves are obtained by measuring the reflected light intensity as a function of the incident angle. The reflected light intensity is minimum at the "SPR angle" or "coupling angle". Changes in refraction index in the region near the gold-solution interface (due to organic molecule adsorption onto the gold surface) result in changes of SPR angle.

Experimental set-up: A thin gold layer (thickness $~ 50 \mathrm{~nm}$ ) was evaporated on a LaSFN9 glass slide $\left(n_{632.8 \mathrm{~nm}}=1.845\right.$, Hellma Optik). The slide was optically coupled to a rightangle LaSFN9 glass prism (Hellma Optik) by using a matching oil (1-iodonaphtalene sulfur, $n=1.700$, SPI). A Teflon flow-cell (volume $1 \mathrm{~mL}$ ) was pressed against a clean microscope slide. The prism/gold slide assembly was then pressed on top of the cell, allowing the gold film to be exposed to the filling solution. A tight sealing was ensured by O-rings. The alignment of the back reflected beam with the incident beam was performed at $45^{\circ}$

The full assembly was mounted on the stage of a stepper-motor driven $\theta / 2 \theta$ goniometer with angular resolution of 0.01 degree (Huber $414 \mathrm{a}$ ), so that the center of the gold slide is at the axis of rotation. The goniometer and data acquisition were controlled through an IEEE interface board (Keithey KPC-488.2, software from Resonant Probe).

A computer-controlled scanning angle apparatus (Resonant Probe Microscopy GmbH, Mainz, Germany) was used to perform the SPR measurements. The incident light was a linearly polarized $\mathrm{HeNe}$ laser (output power $=5 \mathrm{~mW}, \lambda=632.8 \mathrm{~nm}$, JDS Uniphase), attenuated, and p-polarized with respect to the plane of incidence on the gold surface (Glan-Thompson polarizing prism, Halle). The optical signal was modulated to a frequency of $1 \mathrm{kHz}$ (optical chopper, Perkin Elmer 197) and correlated to the detection through a lock-in amplifier (EG\&G PAR 5210).

The light reflected at the metal/prism interface was focused on a silicon photodiode detector and the photodiode signal was measured with the lock-in amplifier in phase with the incident light source.

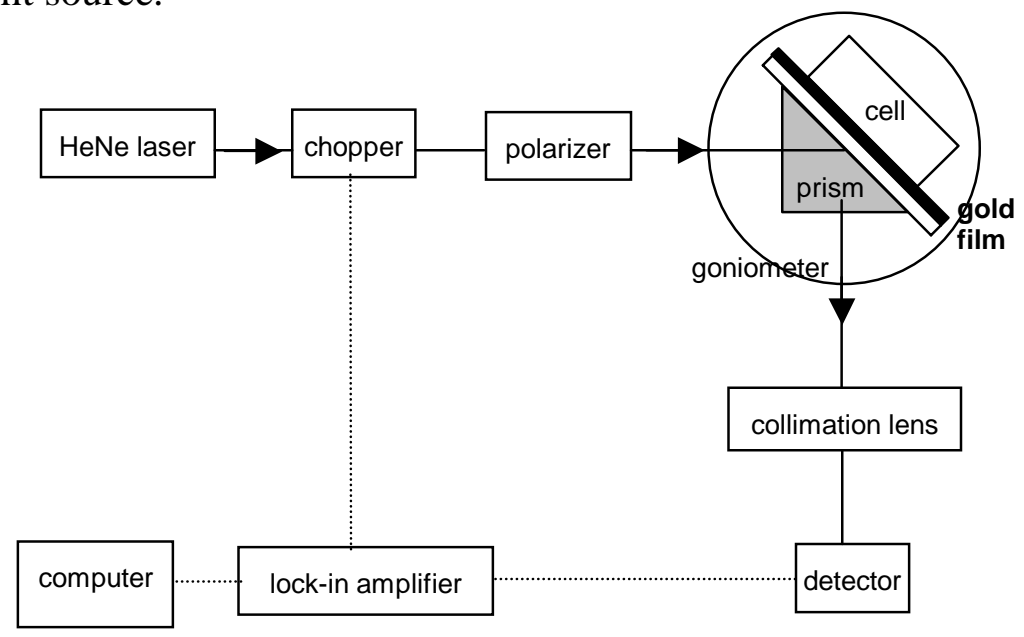


Solutions: All solutions were prepared with Milli-Q water, in glassware washed with boiling $\mathrm{EtOH} / \mathrm{CHCl}_{3}$, rinsed with $\mathrm{EtOH}$, and dried with $\mathrm{N}_{2}$. A 10mM DMAP aqueous solution was prepared. Flushing solution was prepared by adding sodium hydroxide to MilliQ water ( $\mathrm{pH}$ 10.4). For the experiment at $\mathrm{pH} 3.2$, diluted acetic acid was added to DMAP solution.

Flow-cell and gold slides: The flow cell was completely disassembled and each part were washed with boiling $\mathrm{EtOH} / \mathrm{CHCl}_{3}$, rinsed with $\mathrm{EtOH}$, and dried with $\mathrm{N}_{2}$. The LaSFN9 glass slides were carefully washed: sonicated for $5 \mathrm{~min}$ in 5\% Hellmanex soap solution, extensively rinsed with Milli-Q, sonicated for $5 \mathrm{~min}$ in Milli-Q, rinsed, sonicated for 5 min with $\mathrm{EtOH}$, and finally kept in clean EtOH until being used for the gold evaporation. The tweezers used to transfer the slides to the evaporator sample holder and to remove them after gold evaporation were also carefully cleaned with boiling $\mathrm{EtOH} / \mathrm{CHCl}_{3}$. The coated slides were kept in a TLC cuve filled with EtOH $99 \%$ and closed with parafilm. The gold slides were not kept for more than 4 days after evaporation and were dried with $\mathrm{N}_{2}$ before being used.

Data acquisition: The SPR angle tracking vs. time was started (kinetic adsorption data). Once the baseline was stable, DMAP solution was carefully injected in the cell using a syringe, making sure to not form air bubbles. Once a plateau was reached (no more molecule adsorption), the cell was flushed with Milli-Q, typically adjusted to $\mathrm{pH} 10.4$ to prevent the pH-induced desorption of DMAP. Once the SPR angle was stable, the SPR angle tracking experiment was stopped and an SPR curve (reflected light intensity $v s$. incident angle) was acquired.

Example of SPR angle tracking $v s$. time curve (DMAP adsorption).

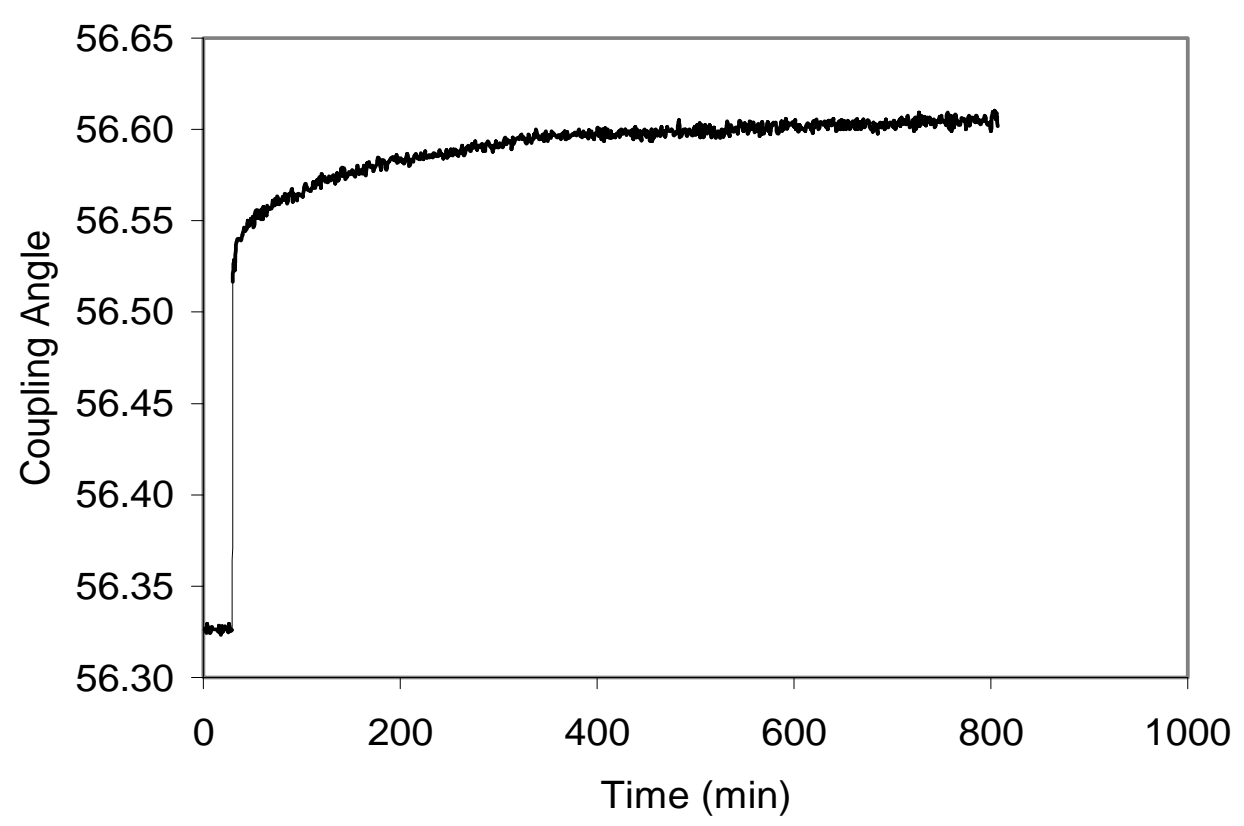




\section{Example of SPR curve}

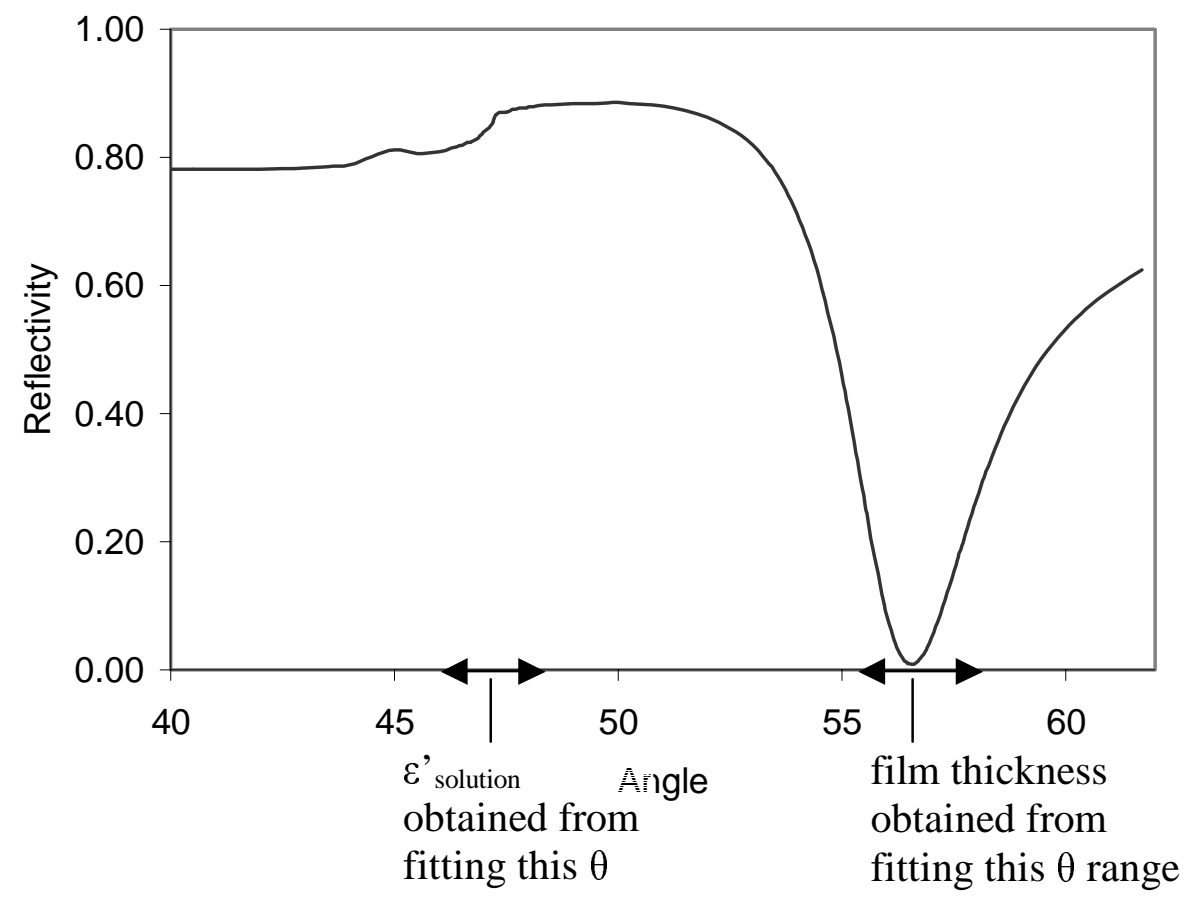

Data analysis: The acquired SPR curves were fitted to simulated curves, generated by the Resonant Probe Software using a multilayer Fresnel optical model.

The exact parameters for the gold layer were obtained from the fitting with Milli-Q water in the cell and kept constant in the next fitting (with DMAP).

After DMAP adsorption, the system consisted of 4 layers and the fitting gave the actual values for the solution dielectric constant and DMAP film thickness.

The values in the following tables were used to generate the simulated curves. The values in italics were then varied in order to make the acquired curve and simulated curve overlap.

\begin{tabular}{|c|c|c|c|c|c|c|c|}
\hline Layer & $\begin{array}{c}\text { Thickness } \\
(\mathrm{nm})\end{array}$ & $\varepsilon^{\prime}$ & $\varepsilon "$ & Layer & $\begin{array}{c}\text { Thickness } \\
\text { (nm) }\end{array}$ & $\varepsilon^{\prime}$ & $\varepsilon^{\prime \prime}$ \\
\hline Prism & 0 & 3.404 & 0 & Prism & 0 & 3.404 & 0 \\
\hline Gold & 50 & -12.9 & 1.2 & Gold & fitting water & fitting $\mathrm{w}$ & fitting $\mathrm{w}$ \\
\hline Water & 0 & 1.777 & 0 & $\begin{array}{l}\text { DMAP } \\
\text { thin film }\end{array}$ & from fitting & 2.25 & 0 \\
\hline & & & & Solution & 0 & 1.777 & 0 \\
\hline
\end{tabular}


Calculations leading to the estimation of the of the bound TOAB concentration for a sample containing $1 \mathrm{mg} \mathrm{Au} / \mathrm{mL}$.

\begin{tabular}{|c|c|}
\hline Radius of $\mathrm{Au}$ atom* $\left(\mathrm{r}_{\mathrm{Au}}\right)$ & $1.62 \AA$ \\
\hline Radius of NP $\left(\mathrm{r}_{\mathrm{NP}}\right)$ & $31 \AA$ \\
\hline $\begin{array}{l}\text { Volume of a NP (a) } \\
4 / 3 \pi \mathrm{r}_{\mathrm{NP}}{ }^{3}\end{array}$ & $124788 \AA^{3}$ \\
\hline $\begin{array}{l}\text { Volume of a } \mathrm{Au} \text { atom (b) } \\
4 / 3 \pi \mathrm{r}_{\mathrm{Au}}{ }^{3}\end{array}$ & $17.81 \AA^{3}$ \\
\hline $\begin{array}{l}\text { \# Au atoms in a NP (c) } \\
\mathbf{c}=\mathbf{a} / \mathbf{b}\end{array}$ & 7006 \\
\hline MW of Au & $196.97 \mathrm{~g} / \mathrm{mol}$ \\
\hline $\begin{array}{l}\text { \#mol of } \mathrm{Au} \text { in the batch }(500 \mathrm{mg} \mathrm{Au})(\mathbf{d}) \\
\mathbf{d}=0.5 / \mathrm{MW}\end{array}$ & $2.54 \mathrm{e}-3 \mathrm{~mol}$ \\
\hline $\begin{array}{l}\# \text { mol of NP in the batch }(\mathbf{e}) \\
\mathbf{e}=\mathbf{d} / \mathbf{c}\end{array}$ & $3.6 \mathrm{e}-7 \mathrm{~mol}$ \\
\hline $\begin{array}{l}\text { Surface of a NP(f) } \\
4 \pi \mathrm{r}_{\mathrm{NP}}^{2}\end{array}$ & $12076 \AA^{2}$ \\
\hline $\begin{array}{l}\text { Footprint of a Au atom }(\mathbf{g}) \\
\pi_{\mathrm{Au}}{ }^{2}\end{array}$ & $8.24 \AA^{2}$ \\
\hline $\begin{array}{l}\# \mathrm{Au} \text { atoms at surface of NP }(\mathbf{h}) \\
\mathbf{h}=\mathbf{f} / \mathbf{g}\end{array}$ & 1465 \\
\hline $\begin{array}{l}\text { Assumed molar ratio adsorbed TOAB } \\
\text { molecule : surface Au atom }\end{array}$ & $1: 2$ \\
\hline $\begin{array}{l}\text { \# TOAB molecule at surf of a NP }(\mathbf{m}) \\
\mathbf{m}=\mathbf{h} / \mathbf{2}\end{array}$ & 732 \\
\hline $\begin{array}{l}\# \text { mol of cluster in batch }(\mathbf{n}) \\
\mathbf{n}=\mathbf{d} / \mathbf{c}\end{array}$ & $3.6 \mathrm{e}-7 \mathrm{~mol}$ \\
\hline $\begin{array}{l}\text { Conc of bound TOAB in batch }(\mathbf{o}) \\
o=n * m\end{array}$ & $2.7 \mathrm{e}-4 \mathrm{~mol} / \mathrm{L}$ \\
\hline
\end{tabular}

*average of the atomic radius of $A u(1.79 \AA)$ and the covalent radius of $A u(1.34 \AA)$. 
Calculations leading to the estimation of the bound DMAP concentration for a sample containing $1 \mathrm{mg} \mathrm{Au} / \mathrm{mL}$.

\begin{tabular}{|c|c|}
\hline Radius of $\mathrm{Au}$ atom $\left(\mathrm{r}_{\mathrm{Au}}\right)$ & $1.62 \AA$ \\
\hline Radius of NP $\left(\mathrm{r}_{\mathrm{NP}}\right)$ & $31 \AA$ \\
\hline $\begin{array}{l}\text { Volume of a NP }(\mathbf{a}) \\
4 / 3 \pi \mathrm{r}_{\mathrm{NP}}{ }^{3}\end{array}$ & $124788 \AA^{3}$ \\
\hline $\begin{array}{l}\text { Volume of a Au atom (b) } \\
4 / 3 \pi r_{A u}^{3}\end{array}$ & $17.81 \AA^{3}$ \\
\hline $\begin{array}{l}\text { \# Au atoms in a NP (c) } \\
\mathbf{c}=\mathbf{a} / \mathbf{b}\end{array}$ & 7006 \\
\hline $\mathrm{MW}$ of $\mathrm{Au}$ & $196.97 \mathrm{~g} / \mathrm{mol}$ \\
\hline $\begin{array}{l}\text { \#mol of Au in the batch }(500 \mathrm{mg} \mathrm{Au})(\mathbf{d}) \\
\mathbf{d}=0.5 / \mathrm{MW}\end{array}$ & $2.54 \mathrm{e}-3 \mathrm{~mol}$ \\
\hline $\begin{array}{l}\# \text { mol of NP in the batch }(\mathbf{e}) \\
\mathbf{e}=\mathbf{d} / \mathbf{c}\end{array}$ & $3.6 \mathrm{e}-7 \mathrm{~mol}$ \\
\hline $\begin{array}{l}\text { Surface of a NP (f) } \\
4 \pi r_{N P}^{2}\end{array}$ & $12076 \AA^{2}$ \\
\hline $\begin{array}{l}\text { Footprint of a Au atom (g) } \\
\pi \mathrm{r}_{\mathrm{Au}}{ }^{2}\end{array}$ & $8.24 \AA^{2}$ \\
\hline $\begin{array}{l}\# \text { Au atoms at surface of NP (h) } \\
\mathbf{h}=\mathbf{f} / \mathbf{g}\end{array}$ & 1465 \\
\hline Footprint of a DMAP molecule (i) & $14.7 \AA^{2}$ \\
\hline $\begin{array}{l}\text { \# DMAP molecule at surf of a NP }(\mathbf{j}) \\
\mathbf{j}=\mathbf{f} / \mathbf{i}\end{array}$ & 821 \\
\hline $\begin{array}{l}\text { \# bound DMAP in batch }(\mathbf{k}) \\
\mathbf{k}=\mathbf{e}^{*} \mathbf{j}\end{array}$ & $2.95 \mathrm{e}-4 \mathrm{~mol}$ \\
\hline $\begin{array}{l}\text { Conc of bound DMAP in a batch }(\mathbf{l}) \\
\mathrm{k} / 0.5 \quad(500 \mathrm{~mL})\end{array}$ & $5.9 \mathrm{e}-4 \mathrm{~mol} / \mathrm{L}$ \\
\hline $\begin{array}{l}\text { Au : DMAP ratio at NP surface } \\
\mathbf{h} / \mathbf{j}: 1\end{array}$ & $1.78: 1$ \\
\hline
\end{tabular}

